Research Article

\title{
Species Composition, Diversity, and Habitat Association of Medium- and Large-Sized Mammals in Chimit-Kolla, Abay Gorge, Ethiopia
}

\author{
Mengistu Wale ${ }^{1}{ }^{1}$ and Mesele Yihune $^{2}$ \\ ${ }^{1}$ Animal Biodiversity Directorate, Ethiopian Biodiversity Institute, P.O. Box 30726, Addis Ababa, Ethiopia \\ ${ }^{2}$ Department of Zoological Science, Addis Ababa University, P.O. Box 1176, Addis Ababa, Ethiopia \\ Correspondence should be addressed to Mengistu Wale; mengw2004@yahoo.com
}

Received 8 March 2021; Revised 18 August 2021; Accepted 7 September 2021; Published 21 September 2021

Academic Editor: Marco Cucco

Copyright (c) 2021 Mengistu Wale and Mesele Yihune. This is an open access article distributed under the Creative Commons Attribution License, which permits unrestricted use, distribution, and reproduction in any medium, provided the original work is properly cited.

\begin{abstract}
Identifying the species distribution, diversity, and habitat association provides input to launch proper conservation interventions. A survey of medium- and large-sized mammal species was conducted in Chimit-Kolla area to assess their distribution, diversity, and relative abundance in November 2019 to September 2020. Line transect sampling and focus group discussions were used for data collection. Shannon diversity index and Sorenson's coefficient were used to compute the diversity and habitat utilization of species. The association of species among habitats was tested using the chi-squared test. In the survey, 18 species of medium- and large-sized mammals belonging to the order Artiodactyla (7 species), Carnivora (6 species), Rodentia (1 species), Primates (3 species) and Tubulidentata (1 species) were recorded. The association of mammalian species among the three habitats was not significant $(p>0.05)$. However, the abundance of mammal species was significantly associated with forest habitats $(p<0.05)$. There was a significant variation in abundance of medium- and large-sized mammal species observed in the dry season (157, $57.5 \%)$ as compared to the wet season $(116,42.5 \%)\left(\chi^{2}=6.17, \mathrm{df}=1\right.$, and $\left.p=0.013\right)$. The most abundant species was olive baboon (Papio anubis), followed by grivet monkey (Chlorocebus aethiops) and crested porcupine (Hystrix cristata). While leopard (Panthera pardus), white-tailed mongoose (Ichneumia albicauda), and aardvark (Orycteropus afer) were the rarest mammalian species recorded. Forest habitat has the highest species diversity $\left(H^{\prime}=2.276\right)$ than riverine vegetation and wooded grassland. Mammal species showed a considerable similarity among habitats, and the highest similarity was recorded between forest and wooded grassland $(S=0.8)$. The study area relatively has considerable numbers of medium- and large-sized mammal species, and urgent conservation action is required to reduce the emerging threats (hunting, charcoal production, agriculture, and investment expansion) and ensure survival of mammal species.
\end{abstract}

\section{Introduction}

Ethiopia is a landlocked country located in the horn of Africa. It is known for having diverse ecosystems and altitudinal variation which ranges from Ras Dashen $(4600 \mathrm{~m}$ a.s.l.) to Danakil Depression (126 m b.s.l.) $[1,2]$. Surprisingly, 50\% the Afrotropical region's land above $2000 \mathrm{~m}$ a.s.l. is found in Ethiopia [3]. These altitudinal variations enable the country to have a range of climate zones, locally called Dega, Woina Dega, Kolla, and Bereha. The mean annual rainfall and temperature of the country range from $500 \mathrm{~mm}$ to $280 \mathrm{~mm}$ and from $10^{\circ} \mathrm{C}$ to $30^{\circ} \mathrm{C}$, respectively [1]. In addition, the Rift Valley bisects the western and eastern plateaus centrally, which acts as a major zoogeographical barrier within the country [2]. The presence of these altitudinal and climatic zonal variabilities in the country greatly contributed to immense diversity of plant and animal species in Ethiopia [3,4].

The combinations of the abovementioned contributing factors make Ethiopia as one of the potential biodiverse countries in Africa. The exact number of recognized mammalian families, genera, and species fluctuates as new 
species are described and scientists make other taxonomic revisions [5]. According to reference [6], there are 311 mammal species in Ethiopia, which belong to 144 genera, 43 families, and 13 orders [5].

Mammals are distributed in almost all habitats and regions of the earth except ice of Antarctica from an elevation below sea level up to $6500 \mathrm{~m}$ above sea level [7]. The majority (98\%) of mammalian species occupy terrestrial habitats [8]. In Ethiopia, medium- and large-sized mammals are widely distributed in a wide range of ecosystem from desert to afro-alpine ecosystem [9].

Mammals play a great role in proper ecosystem structure and functioning $[10,11]$. They can modify vegetation structure, alter pathways of nutrients, and thereby change species composition in the ecosystem [11]. They are participating in different trophic levels in food webs, contributing to herbivore regulation, and acting as important seed dispersers for many tree species $[10,11]$. They are also a vital economic resource for local human populations through their use as food, pets, artifacts, and tourism [12, 13].

However, recently escalating natural and anthropogenic factors greatly threatened survival of mammals. The main natural and human-induced activities that caused the depletion of mammal species include habitat loss and fragmentation $[8,14]$. A recent assessment of the conservation status of mammal species indicated that at least one-fifth of mammal species are at risk of extinction in the wild worldwide [8, 15]. A study on 173 mammals' prehistoric distribution in six continents showed that $50 \%$ of their range area has been lost [15]. Similarly, mammals have been hunted illegally for a century for meat and other purpose even within the national parks in developing countries. As a result, $40 \%$ of currently Critically Endangered mammal species are impacted by hunting [8]. Rapid population growth in developing countries such as Ethiopia and associated increasing demand of agricultural land to increase productivity are predicted to be a main threat of biodiversity [14].

In Ethiopia, mammals in particular and wildlife in general are somewhat conserved in protected areas including national parks, sanctuaries, controlled hunting areas, community conservation areas, and others [16]. However, the rapidly increased anthropogenic and natural factors seriously threatened the wild mammals of Ethiopia including those found in national parks $[17,18]$. As a result, at least 36 mammalian species are threatened in the country [19]. The impact is highly pronounced in large mammals that required large home ranges [20]. The population of African elephant has been declining in Omo National Park and Babille Elephant Sanctuary, mainly due to poaching, habitat loss, and human-elephant conflict that question its survival. This situation is more painful to the world if it happens on endemic mammals.

Impressive progressive studies have been made in mammals of Ethiopia particularly in protected areas recently. However, the fauna of Ethiopia is not well studied and documented as compared to the flora of the country [14], even the diversity and conservation status of mammalian species outside protected areas are poorly known [21, 22]. However, assessing the status of mammal species outside protected areas is equally important even more because of the huge anthropogenic pressures they absorb from their surrounding environments [22, 23]. Therefore, studying the status of wildlife outside protected areas is a precondition to conserve by establishing protected areas based on their potentiality and threat severity of the areas.

Chimit-Kolla is located in Abay Gorge and used as a refugium for wildlife species where their previous adjacent habitats have been destroyed by dense human settlement and agricultural expansion [24]. It is clear that as habitats of wild animals alter, untold numbers of species are disappearing before they have been recognized or studied [25]. In addition, mammals particularly antelopes are hunted illegally without any protection for meat by the local communities which worth the situation in the area.

Chimit-Kolla is not under legal protection yet. Furthermore, there are no well-organized data available about the mammal species diversity and abundance of this area. It is also clear that anthropogenic threats are escalating through time negatively affecting the survival of wildlife as observed in many of our national parks today $[14,26]$. The situation is expected to be more in unprotected areas such as Chimit-Kolla in Abay Gorge. Conducting surveys enables conservationists to act against factors that caused population decline [13].

Therefore, the study aims to survey and document the species composition and habitat association of medium- and large-sized mammals in Chimit-Kolla and provide baseline data for effective conservation of wild animals.

\section{Materials and Methods}

2.1. Description of the Study Area. The study was conducted in Chimit-Kolla located in Chimet kebele in Gozamin district (Figure 1). It is located at the southern end of Chimet kebele in Abay Gorge about $30 \mathrm{~km}$ and $330 \mathrm{~km}$ away from Debre Markos town and Addis Ababa city, respectively. Chimit-Kolla consists of an elongated mountain chain forest called Jibilat-Mutera forest. Chimit-Kolla is boarded by Chemoga River in the east and Wutrin and Tidima stream in the west and north, respectively. The area of Chimit-Kolla is 4200 hectares (unpublished data, Gozamin district office).

The agroclimatic zone of Chimit-Kolla is mainly tropical hot, locally called Kolla [27], with an altitudinal range of $900 \mathrm{~m}$ a.s.l. near Abay River at southern edges and $2080 \mathrm{~m}$ a.s.l at the northern edges. The area received unimodal rainfall pattern, with May to September being the main rainy season, and the mean annual rainfall distribution ranges from 500 to $1500 \mathrm{~mm}$. The mean annual temperature record of the study area is between $20^{\circ} \mathrm{C}$ and $35^{\circ} \mathrm{C}$ (unpublished data, Gozamin district office). The study area is located between coordinates of $10^{\circ} 01^{\prime} 10.82^{\prime \prime}-10^{0} 10^{\prime} 37.47^{\prime \prime} N$ and $37^{0} 28^{\prime} 44.13^{\prime \prime}-37^{0} 34^{\prime} 28.3^{\prime \prime} \mathrm{E}$.

The habitat of the study area was categorized into three vegetation zones: forest, riverine, and wooded grassland. There is no organized study on the natural vegetation of the study area. However, the natural vegetation of the study area 


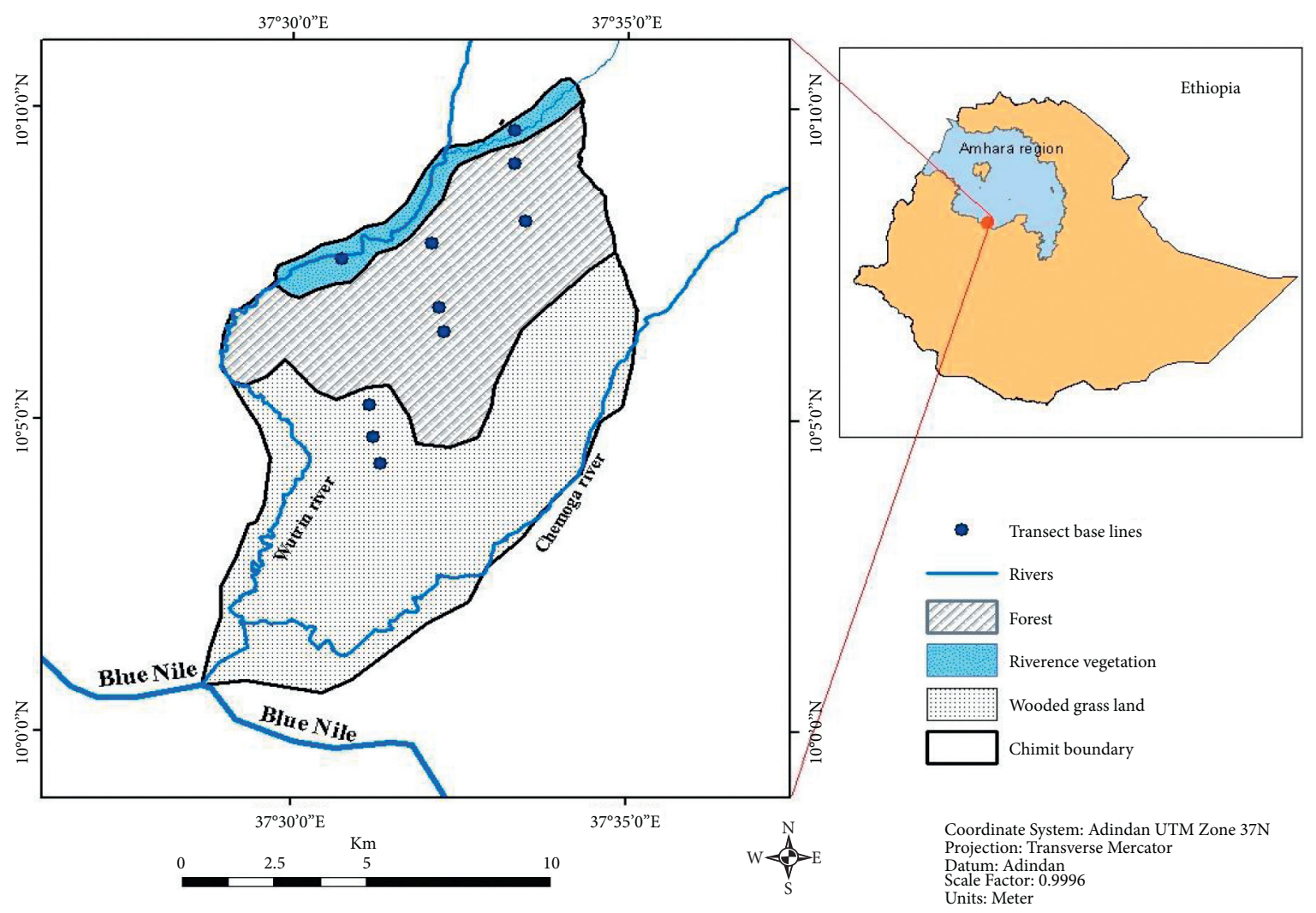

Figure 1: Map of Chimit-Kolla.

is dominated by trees and grasses including family Fabaceae (Acacia bussei, Acacia albida, Acacia abyssinica, and others species), family Moraceae (Ficus sycomorus and Ficus sur), Boswellia species, and Hyparrhenia species (thatching grass).

\section{Methods}

3.1. Sampling Design. A pilot survey was carried out during November 2019 to gather information on accessibility, vegetation structure, and other factors in the study area. The study area was stratified into three vegetation zones: forest, riverine vegetation, and wooded grassland. A line transect sampling method was used to assess diversity and abundance of medium- and large-sized mammals [28]. A total of 10 transects were systematically established considering habitat potentiality and accessibility: five for forest, three for wooded grassland, and two for riverine vegetation. The study was limited in some parts of the study area due to harsh environment, inaccessibility, disturbance, and other factors. The length of transects varied from $1.5 \mathrm{~km}$ for forest, $2.5 \mathrm{~km}$ for wooded grassland to $3 \mathrm{~km}$ for riverine vegetation depending on the topography of the area. Each transect was spaced with $0.5 \mathrm{~km}$ for forest and $1 \mathrm{~km}$ for wooded grassland and riverine vegetation to avoid double counting. The width of each transect also varies depending on the openness or thickness of habitat: $100 \mathrm{~m}$ for forest, $200 \mathrm{~m}$ for wooded grassland, and $50 \mathrm{~m}$ for riverine vegetation.
3.2. Data Collection. Data collection was carried out in December 2019 and September 2020 to account both the dry and the wet season, respectively. The survey of medium- and large-sized mammalian species was conducted by walking on foot along the line transect [29, 30]. Observation of mammals in the field was carried out twice a day, early in the morning $(06: 30-10: 30 \mathrm{~h})$ and late in the afternoon (16: $00-18: 30 \mathrm{~h}$ ) [30]. Silent detection of mammals using a binocular or naked eye was carried out by walking along transect with an average speed of $1.5 \mathrm{~km} / \mathrm{h}$ or less depending on habitat suitability [31,32]. Kingdon [33] field guides were used for further mammal species identification. Some mammal species were identified using indirect methods such as footprints, fecal droppings, scents marks, digging marks, sound, and spines $[28,34]$. Indirect method is an option available to study the distribution and abundance of inaccessible vertebrates such as nocturnal mammals [35]. Additional information for the presence of mammal species was supported by focus group discussion with selected local community using field guides. The presence of potential anthropogenic wildlife threats was also recorded during field observation.

3.3. Data Analysis. Data were analyzed using descriptive statistics. Shannon-Wiener diversity index $\left(H^{\prime}\right)$ was used to calculate the diversity of species using the following formula [36]: $H^{\prime}=-\sum(\mathrm{Pi})(\ln \mathrm{Pi})$, where $\mathrm{H}^{\prime}=$ diversity index, $\ln =$ natural logarithm, and $\mathrm{Pi}=$ proportion of total sample belonging to the $\mathrm{i}^{\text {th }}$ species $(\mathrm{pi}=\mathrm{ni} / \mathrm{N}$, where ni is the 
number of individuals in species $i$ and $N$ is the total number of individuals in the community).

Shannon-Wiener evenness index $(E)$ was used to determine pattern of mammalian species distribution in the habitats and computed using the following formula: $E=H^{\prime}$ / $H_{\text {max }}$, where $H^{\prime}=$ Shannon-Wiener diversity index and $H_{\text {max }}=\ln S$, in which $\ln =$ natural logarithm and $S=$ the total number of species in each habitat. Sorenson's coefficient $(S)$ was used to compare the similarity between two habitats with reference to mammalian species composition and computed with the following formula: $S=2 C / S_{1}+S_{2}$ [37], where $C=$ the number of common species in both habitats, $S_{1}=$ the number of species in habitat one, and $S_{2}=$ the number of species in habitat two. The relative abundance index of species (RAI) was calculated by dividing the number of records of each species by the total number of records of all species. The chi-squared test was used to test significant association of mammal species composition and abundance between different habitats and seasons.

\section{Results}

4.1. Species Composition and Habitat Association. In this survey, a total of 18 species of medium- and large-sized mammals belonging to five orders and nine families were identified from 273 records (Table 1). The order Artiodactyla has the highest number of species (seven species) which belong to the family Bovidae with five species and Suidae with two species. The order Carnivora is represented by six species that belong to four families: Felidae (three species), Hyaenidae, Herpestidae, and Viverridae represented by one species each. While the order Primates is represented by three species in single family, Cercopithecidae. The other two orders Tubulidentata and Rodentia are represented by one family and species each. More than three-quarter of the species were identified by visual encounter, while the remaining species were identified using indirect methods (Figure 2). Crested porcupine (Hystrix cristata), spotted hyena (Crocuta crocuta), leopard (Panthera pardus), African civet (Civettictis civetta), and aardvark (Orycteropus afer) were identified using feces/spine, vocal, scent, holes, and scratches. Leopard was identified by vocal sound at night during the dry season and further confirmed from community discussion and skin collected in farmer house.

The association of medium- and large-sized mammal species composition showed slight variation among habitats. The highest species composition of 17 species was recorded in the forest followed by wooded grassland and the least being riverine vegetation with 13 and 11 species, respectively (Table 2). The variation in species richness among habitats was not significant $\left(\chi^{2}=1.4, \mathrm{df}=2\right.$, and $\left.p=0.492\right)$. Grivet monkey (Chlorocebus aethiops), gureza (Colobus guereza), bushpig (Potamochoerus larvatus), leopard (Panthera par$d u s$ ), and aardvark (Orycteropus afer) were entirely associated with riverine and forest habitats, while greater kudu (Tragelaphus strepsiceros) and oribi (Ourebi ourebi) were restricted in wooded grassland. On the other hand, olive baboon (Papio anubis), crested porcupine (Hystrix cristata), spotted hyena (Crocuta crocuta), common bushbuck
(Tragelaphus scriptus), and common duiker (Sylvicapra grimmia) were considered as habitat generalist in this survey being recorded in all three habitats (Table 3 ).

\subsection{Relative Abundance and Distribution of Mammal Species.} From a total of 273 recorded individuals, the highest number $(N=127)$ was recorded in the forest habitat followed by the wooded grassland $(N=84)$ and the least being riverine vegetation $(N=62)$ (Table 2$)$. The variation in the abundance of mammal species among the three habitats was significant $\left(\chi^{2}=24.02, \mathrm{df}=2\right.$, and $\left.p=0.0001\right)$. In terms of individual species, the most abundant species recorded in the study area was olive baboon followed by grivet monkey and crested porcupine, which account $26.7 \%, 10.6 \%$, and $10 \%$ of the total record, respectively. The rarest mammal species in this study was leopard $(0.3 \%)$ followed by aardvark $1.1 \%$ and whitetailed mongoose accounting $1.5 \%$ of the total record each (Table 3).

The distributional pattern of medium- and large-sized mammal species within their habitats was somewhat evenly distributed across each habitat, but they were more evenly distributed in wooded grassland $(E=0.89)$ than the forest $(E=0.84)$ and riverine vegetation $(E=0.83)$ (Table 2$)$.

There were a greater number of medium- and large-sized mammals observed in the dry season $(157,57.5 \%)$ as compared to the wet season $(116,42.5 \%)$ (Figure 3$)$. The variation was significant $\left(\chi^{2}=6.17, \mathrm{df}=1\right.$, and $\left.p=0.013\right)$ at $95 \%$ confidence interval. Olive baboon is the most abundant species in both seasons but leopard was recorded only in the dry season.

4.3. Species Diversity. Chimit-Kolla had moderate diversity of medium- and large-sized mammal species $\left(H^{\prime}=2.843\right)$. Forest habitat has the highest species diversity $\left(H^{\prime}=2.276\right)$ followed by wooded grassland $\left(H^{\prime}=2.216\right)$, and the least was riverine vegetation $\left(H^{\prime}=1.94\right)$. Mammal species were relatively uniformly distributed in wooded grassland $(E=0.71)$ followed by riverine habitat. However, Simpson dominance index indicated that the riverine vegetation was dominated by few species $(D=0.18)$ followed by forest habitat $(D=0.16)$ (Table 2).

Sorenson's similarity index of medium- and large-sized mammal species among the three habitats prevailed that more than $50 \%$ of species were common among the three habitats. However, the highest similarity of mammal species occurrence was recorded between forest and wooded grassland (0.80) followed by forest and riverine vegetation (0.78), and the least was between wooded grassland and riverine vegetation (0.58).

Based on anecdotal information, the main threats of mammal species in the study area include illegal hunting, investment and agriculture expansion, and charcoaling. Unlike the adjacent highland forest of the district, the study area was not deforested until recently because of its inaccessibility. However, recently, the situation became trouble; investors and unemployed youth are scrambling the area for agriculture and charcoaling. Illegal hunting using shotguns was one of the major threats of medium- and large-sized 
TABLE 1: List of species recorded in Chimit-Kolla.

\begin{tabular}{|c|c|c|c|c|}
\hline Order & Family & Species name & Common name & Identification methods \\
\hline \multirow{8}{*}{ Artiodactyla } & \multirow{3}{*}{ Suidae } & Potamochoerus larvatus & Bushpig & Visual + scratch \\
\hline & & Phacochoerus africanus & Common warthog & Visual \\
\hline & & Oreotragus oreotragus & Klipspringer & Visual \\
\hline & \multirow{5}{*}{ Bovidae } & Ourebia ourebi & Oribi & Visual \\
\hline & & Tragelaphus scriptus & Common bushbuck & Visual \\
\hline & & Tragelaphus strepsiceros & Greater kudu & Visual \\
\hline & & Sylvicapra grimmia & Common duiker & Visual \\
\hline & & Canis mesomelas & Black-backed jackal & Visual \\
\hline \multirow{5}{*}{ Carnivora } & \multirow{2}{*}{ Felidae } & Panthera pardus & Leopard & Vocal + interview \\
\hline & & Leptailurus serval & Serval & Visual \\
\hline & Hyaenidae & Crocuta crocuta & Spotted hyena & Feces \\
\hline & Herpestidae & Ichneumia albicauda & White-tailed mongoose & Visual \\
\hline & Viverridae & Civettictis civetta & African civet & Scent + feces \\
\hline \multirow{2}{*}{ Rodentia } & \multirow{2}{*}{ Hystricidae } & Hystrix cristata & Crested porcupine & Feces + spine \\
\hline & & Chlorocebus aethiops & Grivet monkey & Visual \\
\hline \multirow{2}{*}{ Primates } & \multirow{2}{*}{ Cercopithecidae } & Papio anubis & Olive baboon & Visual \\
\hline & & Colobus guereza & Guereza & Visual \\
\hline Tubulidentata & Orycteropodidae & Orycteropus afer & Aardvark & Holes + scratches \\
\hline
\end{tabular}
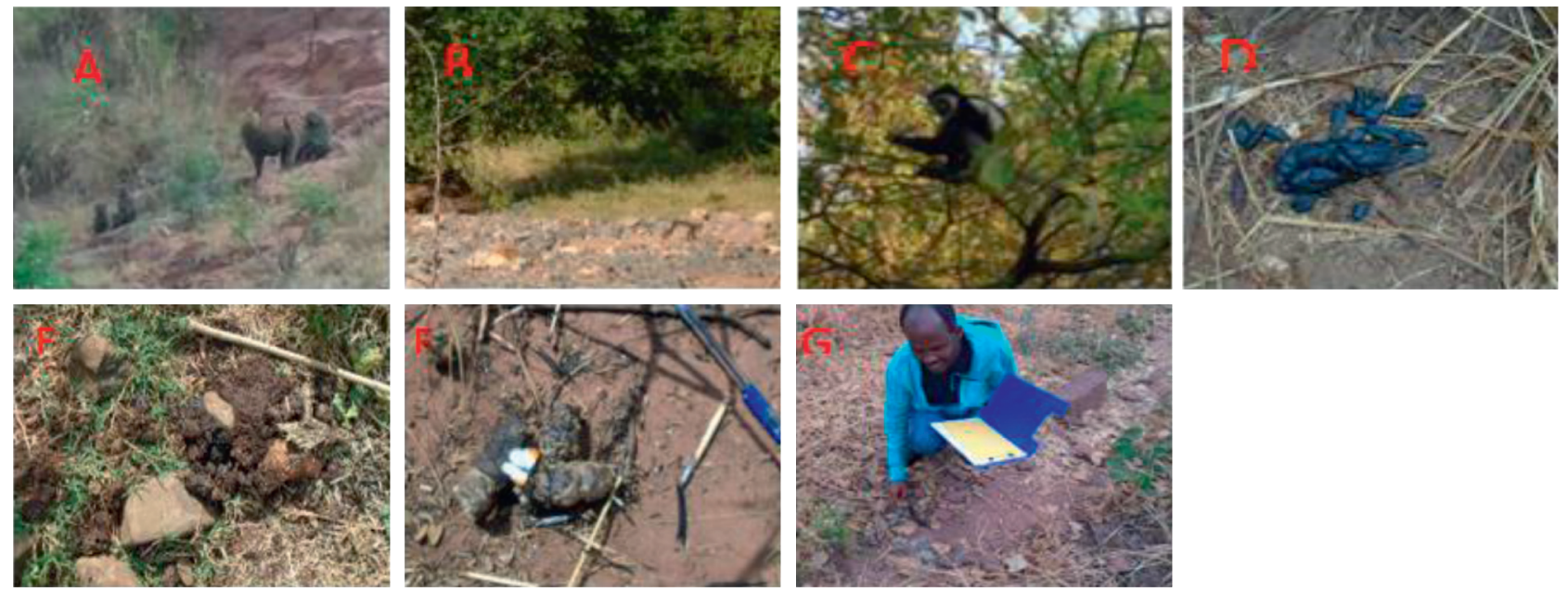

Figure 2: Some photo of mammals and their scat or spine observed during assessment. (a) Olive baboon, (b) grivet monkey, (c) mantled guereza, (d) porcupine scat, (e) civet scat, (f) hyena scat, and (g) scat observation.

TABLe 2: Species diversity and evenness in Chimit-Kolla.

\begin{tabular}{lcccc}
\hline Diversity index & Riverine & Forest & Wooded grassland & Overall diversity indices \\
\hline No. of species & 11 & 17 & 13 & 18 \\
No. of individuals & 62 & 127 & 84 & 273 \\
Shannon-H & 1.944 & 2.276 & 2.216 & 2.483 \\
Dominance-D & 0.1837 & 0.166 & 0.1346 & 0.118 \\
Evenness-e $^{\mathrm{H}} / \mathrm{S}$ & 0.6353 & 0.5726 & 0.7056 & 0.663 \\
\hline
\end{tabular}

mammals in the study area. Hunting seems legal to the local community and practiced for subsistence consumption and for proudness since long time.

\section{Discussion}

In the present study, a total of 18 species medium- and largesized mammals were recorded. The result was in line with 18 species reported in [38], in southeastern Brazil, comparable with 19 species reported in [39] in Wondo Genet, Ethiopia, but lower than the 28 species reported in [30] in Dati Wolel
National Park and 23 species reported in [40] in BorenaSayint National Park. However, it higher than 12 species reported in [41] in Mengaza communal forest, East Gojjam, and in [22] in Wabe forest fragments, Gurage zone, and 15 species reported in [42] in Lebu Natural Protected Area, Southwest Showa. The difference in species richness in the current study may attribute to variation in habitats, limited period of the study, conservation status, and degree of anthropogenic disturbance.

The distribution of mammalian species is usually affected by availability of suitable habitats and food sources 
TABLE 3: Habitat association and relative abundance of mammal species among habitats.

\begin{tabular}{|c|c|c|c|c|c|}
\hline \multirow{2}{*}{ Scientific name } & \multicolumn{3}{|c|}{ Habitat types } & \multirow{2}{*}{ Total } & \multirow{2}{*}{ RA (\%) } \\
\hline & Riverine & Forest & WG & & \\
\hline Potamochoerus larvatus & 1 & 5 & 0 & 6 & 2.2 \\
\hline Phacochoerus africanus & 2 & 6 & 1 & 9 & 3.3 \\
\hline Oreotragus oreotragus & 0 & 8 & 6 & 14 & 5.1 \\
\hline Ourebi ourebi & 0 & 1 & 15 & 16 & 5.9 \\
\hline Tragelaphus scriptus & 2 & 7 & 3 & 12 & 4.4 \\
\hline Tragelaphus strepsiceros & 0 & 0 & 6 & 6 & 2.2 \\
\hline Sylvicapra grimmia & 2 & 12 & 8 & 22 & 8.1 \\
\hline Canis mesomelas & 1 & 3 & 6 & 10 & 3.7 \\
\hline Leptailurus serval & 0 & 3 & 2 & 5 & 1.8 \\
\hline Crocuta crocuta & 2 & 5 & 4 & 11 & 4 \\
\hline Ichneumia albicauda & 0 & 3 & 1 & 4 & 1.5 \\
\hline Civettictis civetta & 5 & 1 & 0 & 6 & 2.2 \\
\hline Hystrix cristata & 3 & 5 & 20 & 28 & 10 \\
\hline Chlorocebus aethiops & 14 & 15 & 0 & 29 & 10.6 \\
\hline Papio anubis & 17 & 45 & 11 & 73 & 26.7 \\
\hline Colobus guereza & 13 & 5 & 0 & 18 & 6.6 \\
\hline Orycteropus afer & 0 & 2 & 1 & 3 & 1.1 \\
\hline Panthera pardus & 0 & 1 & 0 & 1 & 0.3 \\
\hline
\end{tabular}

$\mathrm{WG}=$ wooded grassland; $\mathrm{RA}=$ relative abundance.

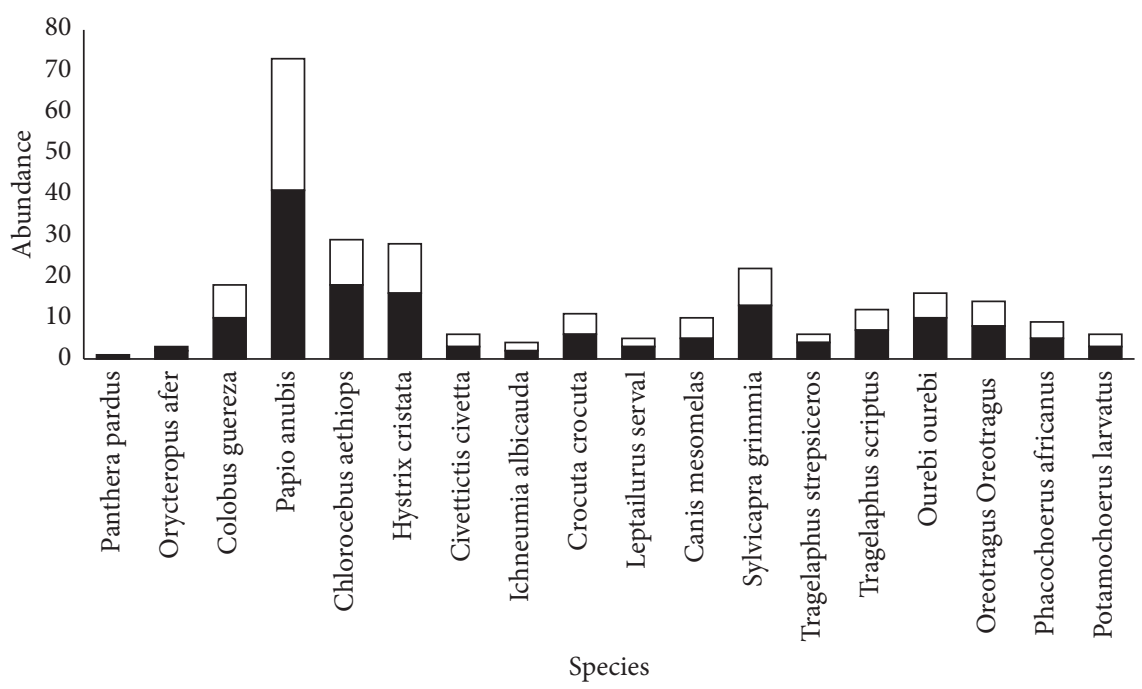

Dry

$\square$ Wet

FIGURE 3: Seasonal variation in abundance of medium- and large-sized mammal species.

[41, 43, 44]. Mammal species diversity is often positively correlated with increase of food availability (presence of variety of plant species, fruits, buds, insects, and others), water, and the presence of subhabitats $[30,43]$. The highest mammal species richness and diversity are associated with forest habitat in this study, probable due to its relative suitability for food source and shelter as compared to wooded grassland and riverine vegetation. Similar studies showed the association of mammal species richness with forest habitat in Ethiopia [30, 41, 43]. For example, forest habitat in the study area has heterogonous range of habitats including chain of mountains and flat plains that enable to have different subhabitats for shelter and provide different source food for different species. In addition, arboreal species are forest specialist restricted in foraging fruits, leaf buds, and seed plant species in the forest, hence contribute more to species diversity. Other mammal species including bushpig, common bushbuck, common duiker, klipspringer, leopard, common warthog, and white-tailed mongoose are associated mainly in the forest probably for these reasons. However, terrestrial large mammals are mostly associated with wooded grasslands or open grasslands than forest and shrubland [8]. Similarly, in the present study, greater kudu and ourebi are entirely associated with the wooded grassland than forest and riverine vegetation. The reason might be linked with the feeding habits (some amount of its diet composition is grass) and easy detection of its predators at a distance. 
In contrast, anthropogenic disturbances cause a change in spatial distribution and fragmentation in the natural habitats which in turn limit mammalian species distribution [45]. The lowest mammalian species diversity recorded in riverine vegetation in this study is probably due to small area coverage and disturbance. Similar result was reported from Borena Saint National Park [40]. Mammal species diversity positively correlated with increased area coverage [46]. The riverine vegetation has small area coverage than forest and wooded grassland. It also faced frequent human disturbance for resource use as it is relatively closer to settlement, which limits food accesses and free moment of animals, hence mammal species preferred relatively safe area, the forest.

In the present study, the distributional patterns of medium- and large-sized mammal species are evenly distributed in wooded grassland, and this contradicts with other studies reported on forest [43], agroforestry [39], and scrubland [22]. The relatively even distribution of mammal species in the present study might be due to uniformity of the habitat and dispersion of resources.

Detection of animals in the forest is difficult due to reduced visibility and silent behavior of some mammals [35]. In contrast to this, most of the mammal species in this study were recorded in the forest habitat. Yalden [47] reported similar result in southwest Cameron. This is because forest habitat in the study is relatively open (not uniformly thick) and one can detect animal at distance. In addition, higher disturbance in nearby wooded grassland and riverine vegetation might cause mammals to aggregate in forest habitat, which increase their detection.

The most abundant species recorded in the present study are primates, olive baboon followed by grivet monkey. Both species are mostly associated with forest and riverine vegetation. Several studies have showed the abundance of primates in forest habitat $[42,43,48]$. The abundance of primates may be attributed to their high reproductive success [49], successful invasions of a variety of types of habitat, including desert, swamp, forest, and montane environments [50], the diversified foraging behavior $[49,50]$, and tolerance to human disturbance [22]. The presence of rocky mountain cliff in the study area probably creates good opportunities to escape from predators such as Panthera pardus, thereby contributing to their success. In contrary, the rareness of leopard (Panthera pardus), aardvark (Orycteropus afer), and white-tailed mongoose (Ichneumia albicauda) in the study might be associated with hunting (hunting leopard for skin and medicinal value) and cryptic nature of these mammals. Reports by $[40,43]$ strengthen the present finding of the rareness of leopard in many parts of the country.

In the present study, a relatively high number of species abundance was recorded in dry season. Similar results were reported by different studies in several parts of the Ethiopia and elsewhere $[39,41]$. The reason why a greater number of medium- and large-mammal species observed during the dry season is attributed to an increased visibility. During the dry season, much of the grassland and forest is burnt by wildlife or deliberately human ignition and also lack of rain caused drying of most of herbaceous plants which leads to easy detection wild animals.
Mammal species showed some degree of habitat association. In the present study, a considerable highest similarity of occurrence of mammal species was observed between natural forest and wooded grassland. However, this finding contradicts with other reports elsewhere in Ethiopia, scrubland and forest [22] and woodland and riverine forest [48]. The high mammal species similarity in forest and wooded grassland in the present study may attribute to the large area coverage unlike riverine vegetation which is very small to harbor a greater number of species. Most of olive baboon foraging activity is restricted to forest and wooded grassland and sleeping in the cliffs of the forest.

\section{Conclusion and Recommendations}

Assessment of medium- and large-sized mammals in Chimit-Kolla revealed the presence of relatively considerable number of species. Primates dominate most of the species confined to forest habitat, which are relatively tolerant to human disturbance. Carnivore animals such as leopard and white-tailed mongoose are rare, while large ungulate such as greater kudu and bushbuck are less abundant, indicting presence of disturbance and their intolerance to disturbance. Despite threats facing in the study area not well addressed and need further study, escalating investment and agriculture, charcoal production, and persistent hunting are the major threats threatening the survival of mammals in the study areas. The study acts as refugia to animals that chased as a result of habitat deterioration in most of the human dominated highland areas of the district. However, the area is not under legal protection and such rapidly increased exploitation of the resources will vanish them in short period. Therefore, the following ideas are recommended to conserve the biodiversity in the study area:

(i) Chimit-Kolla has relatively wildlife potential area, so it has to be under legal protection by the concerned bodies.

(ii) A comprehensive study on threats facing by wild animals in the study area is crucial to establish immediate conservation action to regulate irregularities.

(iii) The study area has amazing topography and is closer to Debre Markos (Zonal Town). Therefore, improving the wildlife resources will add tremendous ecotourism values to communities in future.

\section{Data Availability}

The data used to support the findings of this study are available from the corresponding author upon request.

\section{Conflicts of Interest}

The authors declare that there are no conflicts of interest.

\section{Acknowledgments}

The authors would like to acknowledge Chimet kebele local communities and Gozamin district experts who assisted in 
the field survey. Also, they would like to thank Bahir Dar Biodiversity Center for transport service and field assistance and Tadesse Hundum for preparing the study area map. The authors express gratitude to the Ethiopian Biodiversity Institute for financial support.

\section{References}

[1] A. Bekele and D. W. Y. Yalden, The Mammals of Ethiopia and Eritrea, Addis Ababa University Press, Addis Ababa, Ethiopia, 2013.

[2] G. Alves, M. O. Junior, and V. C. Brites, "Medium and largesized mammals of a fragment of cerrado in the triângulo mineiro region, southeastern Brazil bioscience," Journal of Uberlandia, vol. 30, no. 3, pp. 863-873, 2014.

[3] A. Fetene, K. Yeshitela, and E. Gebremariam, "The effects of anthropogenic landscape change on the abundance and habitat use of terrestrial large mammals of Nech Sar National Park," Environment System Research, vol. 8, no. 19, pp. 1-16, 2019.

[4] M. S. Bismark, "Standard operating procedure (sop) for survey of biodiversity in conservation area," Technical Report No 12, Center for Climate Change and Policy Research and Development, Java, Indonesia, 2011.

[5] K. S. Bobo, T. O. W. Kamgaing, C. B. Ntumwel et al., "Large and medium sized mammal species association with habitat type in Southeast Cameroon," Tropical Ecology, vol. 58, no. 2, pp. 379-388, 2017.

[6] J. Borkowski and K. Furubayashi, "Seasonal and diet variation in-group size among Japanese sika deer in different habitats," Journal of Zoological London, vol. 245, pp. 29-34, 1989.

[7] S. T. Buckland, D. R. Anderson, K. P. Burnham, and J. L. Laake, Distance Sampling: Estimating Abundance of Biological Populations, Chapman and Hall, London, UK, 1993.

[8] C. J. Burgin, J. P. Colella, P. L. Kahn, and N. S. Upham, "How many species of mammals are there?" Journal of Mammalogy, vol. 99, no. 1, pp. 1-14, 2018.

[9] G. Ceballos and P. R. Ehrlich, "Mammal population losses and the extinction crisis," Science, vol. 296, pp. 904-907, 2002.

[10] C. Adugna and A. Bekele, "A preliminary survey of medium and large-sized mammals from Lebu Natural Protected Forest, Southwest Showa, Ethiopia," Ecology and Evolution, vol. 9, pp. 12322-12331, 2019.

[11] M. J. Conroy and J. P. Carroll, Quantitative Conservation of Vertebrates, Blackwell Publishing, Hoboken, NJ, USA, 2009.

[12] L. P. Costa, Y. L. R. Leite, S. L. Mendes, and A. D. Ditchfield, "Mammal conservation in Brazil," Conservation Biology, vol. 19, no. 3, pp. 672-679, 2005.

[13] D. Negeri, T. Gadisa, and T. Habitamu, "The diversity, distribution and relative abundance of medium and large-sized mammals in baroye controlled hunting area, illubabor zone, southwest Ethiopia," International Journal of Molecular Evolution and Biodiversity, vol. 5, no. 4, pp. 1-9, 2015.

[14] Ethiopian Biodiversity Institute, Ethiopia's National Biodiversity Strategy and Action Plan 2015-2020, Ethiopian Biodiversity Institute, Addis Ababa, Ethiopia, 2015.

[15] G. Feng, H. Yan, and X. Yang, "Climate and food diversity as drivers of mammal diversity in Inner Mongolia," Ecology and Evolution, vol. 9, no. 4, pp. 2142-2148, 2019.

[16] G. A. B. d. Fonseca, "Small mammal species diversity in Brazilian tropical primary and secondary forests of different sizes," Revista Brasileira de Zoologia, vol. 6, no. 3, pp. 381-422, 1989.
[17] E. M. Gese, "Survey and census techniques for canids," in Canids: Foxes, Wolves, Jackals and Dogs, C. Sillero-Zubiri, M. Hoffman, and D. W. Macdonald, Eds., pp. 273-279, Canid Specialist Group, Gland, Switzerland and Cambridge, UK, 2004.

[18] G. Atnafu and M. Yihune, "Species composition and relative abundance of medium and large mammals in Mengaza communal forest, East Gojjam, Ethiopia," Journal of Ecology and the Natural Environment, vol. 10, no. 2, pp. 34-40, 2018.

[19] G. Shanko, "Review on challenges and opportunities of protected area management in Ethiopia," Journal of Tourism, Hospitality and Sports, vol. 30, pp. 2312-5179, 2017.

[20] G. Mengesha and A. Bekele, "Density, distribution and habitat association of large mammals of Alatish, North Gonder, Ethiopia," Acta Entomologica Sinica, vol. 51, pp. 1099-1128, 2008.

[21] Grzimek's Animal Life Encyclopedia, M.Hutchins, Devra, and Kleiman, Eds., vol. 12-16 Gale Group, Farmington Hills, Michigan, USA, 2nd edition, p. 587, Mammals I-V, 2003.

[22] M. Hoffmann, J. L. Belant, J. S. Chanson et al., "The changing fates of the world's mammals," Philosophical Transaction of the Royal Society, vol. 366, pp. 2598-2610, 2016.

[23] C. M. Johnson, L. Swedell, and J. M. Rothman, "Feeding ecology of Olive baboons (Papio anubis) in Kibale National Park, Uganda: preliminary results on diet and food selection," Afrotropical Journal of Ecology, vol. 50, no. 3, pp. 367-370, 2012.

[24] K. Legese, A. Bekele, and S. Kiros, "A Survey of large and medium-sized mammals in Wabe forest fragments, Gurage zone, Ethiopia," International Journal Avian and Wildlife Biology, vol. 4, no. 2, pp. 32-38, 2019.

[25] C. J. Krebs, Ecological Methodology, Addison Wesley educational publisher, New York, USA, 1999.

[26] J. Kingdon, The Kingdon Field Guide to African Mammals, Bloomsbury Publishing, Plc. London, England, 2nd edition, 2015.

[27] T. H. Larsen, Core Standardized Methods for Rapid Biological Field Assessment, Conservation International, Arlington, USA, 2016.

[28] L. A. Lavrenchenko and A. Bekele, "Diversity and conservation of Ethiopian mammals: what have we learned in 30 years?" Ethiopian Journal of Biological Sciences, vol. 16, no. Suppl, pp. 1-20, 2017.

[29] L. Lavrenchenko, L. Voyta, and R. Hutterer, "Diversity of shrews in Ethiopia, with the description of two new species of Crocidura," Zootaxa, vol. 4196, no. 1, pp. 038-060, 2016.

[30] M. Tefera, "Wildlife in Ethiopia: endemic large mammals," World Journal of Zoology, vol. 6, no. 2, pp. 108-116, 2011.

[31] M. Chane and S. Yirga, "Diversity of medium and large-sized mammals in borena-sayint national park, south wollo, Ethiopia," International Journal of Sciences: Basic and Applied Research, vol. 15, no. 1, pp. 95-106, 2014.

[32] M. Kasso and A. Bekele, "Threats to mammals on fragmented habitats around asella town, Central Ethiopia," International Journal of Biodiversity, vol. 2014, Article ID 903898, 7 pages, 2014.

[33] M. Seid and B. Taye, "Impacts of human activities on wildlife: the case of nile lechwe (Kobus megaceros) gambella national park, southwest Ethiopia," International Journal of Biodiversity and Conservation, vol. 11, no. 1, pp. 48-57, 2019.

[34] M. Geleta and A. Bekele, "Survey of medium and large-sized mammals in wacha protected forest, western Ethiopia," Journal of Agricultural Science, vol. 6, no. 3, pp. 71-79, 2016. 
[35] N. Amsalu, Y. Bezie, M. Fentahun, A. Alemayehu, and G. Amsalu, "Use and conservation of medicinal plants by indigenous people of Gozamin wereda, east Gojjam zone of amhara region, Ethiopia: an ethnobotanical approach," Evidence-based Complementary and Alternative Medicine, vol. 2018, Article ID 2973513, 23 pages, 2018.

[36] R. Gonfa, T. Gadisa, and T. Habitamu, "The diversity, abundance and habitat associations of medium and largesized mammals in Dati Wolel National Park, western Ethiopia," International Journal of Biodiversity and Conservation, vol. 7, pp. 112-118, 2018.

[37] G. E. Shannon and W. Weaver, The Mathematical Theory of Communication, University of Illinois Press, Chicago, Illinois, US, 1949.

[38] S. Sinclair, "The role of mammals as ecosystem landscapers," Alces, vol. 39, pp. 161-176, 2003.

[39] W. D. Sintayehu, "The african elephant (Loxodonta africana) in Ethiopia: a review," European Journal of Biological Sciences, vol. 8 , no. 1, pp. 8-13, 2016.

[40] W. J. Sutherland, Ecological Census Techniques, Handbook, Cambridge University Press, Cambridge, UK, 1996.

[41] J. Terborgh, "Maintenance of diversity in tropical forests," Biotropica, vol. 24, no. 2, pp. 283-292, 1992.

[42] T. Tsegaye, "Assessment of land use/land covers dynamics and soil erosion estimation for sustainable management of land resources, A case study in Gozamin woreda, amhara region, and North Central Ethiopia," M.S. thesis, Addis Ababa University, Addis Ababa, Ethiopia, 2007.

[43] D. Vreugdenhil, A. D. Vreugdenhil, T. Tilahun, A. Shimelis, and Z. Tefera, Gap Analysis of the Protected Areas System of Ethiopia, with technical contributions from Nagelkerke et al, World Institute for Conservation and Environment, USA, 2012.

[44] D. Western, S. Russell, and I. Cuthill, "The status of wildlife in protected areas compared to non-protected areas of Kenya," PloS One, vol. 4, no. 7, 2009.

[45] A. Whiten, R. W. Byrne, R. A. Barton, P. G. Waterman, and S. P. Henzi, "Dietary and foraging strategies of baboons," Philosophical Transactions of the Royal Society of London, vol. 334, no. 1270, pp. 187-197, 1991.

[46] E. O. Wilson, "Threats to biodiversity," Scientific American, vol. 261, no. 3, pp. 108-116, 1989.

[47] D. W. Yalden, "The extent of high ground in Ethiopia compared to rest of Africa," Sinet: Ethiopian Journal of Science, vol. 6, pp. 35-38, 1983.

[48] D. W. Yalden and M. J. Largen, "The endemic mammals of Ethiopia," Mammal Review, vol. 22, no. 3-4, pp. 115-150, 1992.

[49] J. Young, A Reference Guide for Future Strategic Planning and Project Funding, Ethiopian Protected Areas, a "Snapshot", Addis Ababa, Ethiopia, 2012.

[50] Z. Girma, Y. Mamo, and M. Ersado, "Species composition, distribution and relative abundance of large mammals in and around Wondo Genet Forest Patch, Southern Ethiopia," Asian Journal of Applied Sciences, vol. 5, no. 8, pp. 538-551, 2012. 